\title{
KEJADIAN STUNTING DI PUSKESMAS PANJANG BANDAR LAMPUNG
}

\author{
Nurul Isnaini1), Anggraini2) \\ 'Dosen Fakultas Kedokteran Program Studi DIV Kebidanan Universitas Malahayati \\ Email: isnaininurul50@yahoo.co.id \\ 2Dosen Program Studi DIII Kebidanan Universitas Malahayati Bandar Lampung \\ Email: albarr_arsenio@yahoo.com
}

\begin{abstract}
Background: Based on World data, since 2012 there are 162 million balita to experience stunting. If a continue trend without efforts to reduce stunting, projected to be 127 million in the year of 2025. Obtained as many as $56 \%$ child with stunting condition to live in Asia and $36 \%$ in Afrika. Basic Health Research, The precentation of short children (stunting) showed no signifikan improvement. Since 2007 by 36\%, since 2010 is down to be 35,6\%, Since 2013 increased again by 37,2\% (Kemenkes RI, 2016)

Purpose: The purpose of this study is known incident Stunting at Puskesmas Panjang Bandar lampung in since 2019

Methods: This research is Kuantitatif, with Deskriptif design research. The population is all children under the age of two years old at Puskesmas Panjang Bandar Lampung was obtained from Mei 2019 amount of 3.931 child. The sample is 591 child. The Technique sampling with stratified random sampling. Analise. Data analysis is Analysis Univariate $39,95 \%$

Result: The result of analysis Univariate is incident of Stunting at Puskemas Panjang Bandar Lampung of

Conclusion: The Incident Stunting at Puskesmas Panjang Kota Bandar Lampung of 39,95\%

Sugestion: Data from the results of this study can be a reference for conducting activities in the form of providing information both through print media, electronic media and social media about stunting prevention
\end{abstract}

Key word: The incident of Stunting, Child under two years old

\section{ABSTRAK}

Latar belakang: Berdasarkan data Dunia, tahun 2012 terdapat 162 juta balita mengalami stunting,jika tren berlanjut tanpa upaya penurunan,diproyeksikan akan menjadi127 juta pada tahun 2025 . Sebanyak $56 \%$ anak dengan kondisi stunting hidup di Asia dan 36\% diAfrika.Hasil Riskesdas (Riset Kesehatan Dasar) persentase balita pendek (stunting) tidak menunjukkan perbaikan yang signifikan. Tahun 2007 sebesar 36,8\%, tahun 2010 turun menjadi 35,6\%, tahun 2013 kembali meningkat sebesar 37,2\% (Kemenkes RI. 2016).

Tujuan Penelitian: Diketahui Kejadian Stunting di Puskesmas Kota Bandar Lampung Tahun 2019

Metode Penelitian: Jenis Penelitian adalah Kuantitatif, dengan rancangan penelitian Deskriptif. Populasi dalam penelitian ini adalah seluruh anak usia bawah dua tahun yang ada di Puskesmas Panjang Kota Bandar Lampung diperoleh dari bulan Mei tahun 2019 berjumlah 3.931 anak, sampel 591 anak. Teknik sampel denganstratified random sampling. Analisa yang digunakan adalah analisa Univariat

Hasil: Hasil analisa Univariat didapatkan Kejadian stunting di Puskesmas Panjang Kota Bandar Lampung sebesar 39,95\%.

Kesimpulan: Kejadian stunting di Puskesmas Panjang Kota Bandar Lampung sebesar 39,95\%.

Saran: Data hasil penelitian ini dapat menjadi acuan untuk melakukan kegiatan berupa pemberian informasi baik melalui media cetak, media elektronik maupun media sosial tentang pencegahan stunting

Kata Kunci: Kejadian stunting, Anak usia bawah dua tahun

\section{PENDAHULUAN}

Pembangunan kesehatan dalam periode tahun 2015-2019 difokuskan pada empat program prioritas yaitu penurunan Angka Kematian Ibu dan Bayi, penurunan prevalensi balita pendek (stunting), pengendalian penyakit menular dan pengendalian penyakit tidak menular. Upaya penurunan prevalensi stunting menjadi salah satu prioritas pembangunan nasional yang tercantum didalam 
sasaran pokok Rencana Pembangunan Jangka MenengahTahun 2015-2019.

Saat ini stunting menjadi topik perbincangan di dunia gizi dan kesehatan karena salah satu masalah gizi ini menjadi ancaman terbesar bagi kualitas hidup manusia di masa mendatang. Tidak hanya mengenai tinggi badan, stunting menjadi penting untuk diberantas karena terkait dengan hambatan pertumbuhan otak anak, penurunan kualitas belajar hingga penurunan produktivitas di usia dewasa dan ancaman peningkatan penyakit tidak menular (obesitas, hipertensi, diabetes mellitus, dsb).

Menurut Keputusan Menteri Kesehatan Nomor 1995/MENKES/SK/XII/2010 tentang Standar Antropometri Penilaian Status Gizi Anak, pengertian pendek dan sangat pendek adalah status gizi yang didasarkan pada indeks Panjang Badan menurut Umur (PB/U) atau Tinggi Badan menurut Umur (TB/U) yang merupakan padanan istilah stunted (pendek) dan severely stunted (sangat pendek). Balita pendek (stunting )dapat diketahui bila seorang balita sudah diukur panjang atau tinggi badannya, lalu dibandingkan dengan standar, dan hasilnya berada di bawah normal.

Lima tahun pertama kehidupan anak merupakan periode pertumbuhan otak yang sangat pesat (gold period), yang mendukung seluruh proses pertumbuhan anak dengan sempurna. Periode ini penting karena kekurangan gizi pada periode emas tidak dapat diperbaiki pada periode selanjutnya dan berpotensi untuk mengalami stunting (Achadi, LA. 2012)

Berdasarkan data Dunia, tahun 2012 terdapat 162 juta balita mengalami stunting, jika tren berlanjut tanpa upaya penurunan, diproyeksikan akan menjadi127juta pada tahun 2025.Sebanyak $56 \%$ anak dengan kondisi stunting hidup di Asia dan 36\% diAfrika. Hasil Riskesdas (Riset Kesehatan Dasar) persentase balita pendek (stunting) tidak menunjukkan perbaikan yang signifikan. Tahun 2007 sebesar 36,8\%, tahun 2010 turun menjadi 35,6\%, tahun 2013 kembali meningkat sebesar 37,2\% (Kemenkes RI. 2016)

Pada tahun 2015 pemerintah melalui Kementrian Kesehatan RI melakukan Pemantauan Status Gizi (PSG) dengan hasil sebesar 29\% balita Indonesia mengalami stunting, dimana angka tersebut tertinggi bila dibandingkan dengan Negara
Asia lainnya. (Kemenkes RI, 2016) Provinsi Lampung merupakan salah satu provinsi dengan persentase balita pendek diatas rata - rata nasional yaitu sebesar 42,64\%(Dinas Kesehatan Provinsi Lampung.2016).

Menurut WHO, prevalensi balita pendek menjadi masalah kesehatan masyarakat jika prevalensinya $20 \%$ atau lebih. Karena persentase balita pendek di Indonesia masih tinggi dan merupakan salah satu masalah kesehatan yang harus ditanggulangi serta mengingat begitu besarnya dampak yang akan dirasakan dari balita dengan stunting peneliti ingin melakukan penelitian dengan judul "Kejadian Stunting di Puskesmas Panjang Kota Bandar Lampung Tahun 2018"

\section{METODOLOGI PENELITIAN}

Jenis Penelitian adalah Kuantitatif. Dengan rancangan Deskriptif. Populasi dalam penelitian ini adalah seluruh anak usia bawah dua tahun yang ada di Puskesmas Panjang Kota Bandar Lampung. Berdasarkan data yang diperoleh dari Puskesmas Panjang bulan Mei tahun 2019 berjumlah 3.931 anak. Sampel ditentukan dengan bantuan table Cohen Manion dan Morrison dengan taraf keyakinan 95\% dan interval keyakinan (alpha) 0,05, sehingga dari table didapatkan jumlah sampel sebesar 591 anak usia bawah dua tahun. Teknik pengambilan sampel menggunakan stratified random sampling. Variabel dalam penelitian ini adalah Kejadian Stunting. Instrumen penelitian menggunakan lembar observasi dan Buku KIA responden. Analisa data yang digunakan adalah Analisa Univariat dengan menggunakan distribusi frekuensi.

\section{HASIL DAN PEMBAHASAN}

Berdasarkan Tabel 1 dari 591 responden di Puskesmas Panjang Kota Bandar Lampung Tahun 2019 yang dijadikan sampel penelitian didapatkan karakteristik responden sebagai berikut, umur ibu $490(82,91 \%) 20$ - 35 tahun, pendidikan ibu 312 $(52,79 \%)$ SMA, pekerjaan ibu 591 (100\%) IRT, pendapatan keluarga $423(71,57 \%)$ Rp 1.500 .000 Rp 2.500.000, jumlah anggota keluarga dalam serumah $554(93,74 \%) \leq$ 4orang, jenis kelamin anak $338(57,19)$ perempuan, berat lahir anak 562 $(95,09) 2500$ - 4000 gram, status ASI $458(77,50 \%)$ eksklusif, status imunisasi $440(74,45 \%)$ lengkap. 
Tabel 1 Karakteristik Responden di Puskesmas Panjang Bandar Lampung Tahun 2019

\begin{tabular}{|c|c|c|c|c|c|c|c|c|c|c|}
\hline \multirow{3}{*}{ Karakteristik } & \multicolumn{8}{|c|}{ Kategori } & \multirow{2}{*}{\multicolumn{2}{|c|}{ Total }} \\
\hline & \multicolumn{2}{|c|}{ Sangat Pendek } & \multicolumn{2}{|c|}{ Pendek } & \multicolumn{2}{|c|}{ Normal } & \multicolumn{2}{|c|}{ Tinggi } & & \\
\hline & $\mathrm{n}$ & $\%$ & $\mathrm{n}$ & $\%$ & $\mathrm{~N}$ & $\%$ & $\mathrm{n}$ & $\%$ & $\mathrm{n}$ & $\%$ \\
\hline \multicolumn{11}{|l|}{ Umur Ibu } \\
\hline$-\quad<20$ th & 0 & 0 & 0 & 0 & 4 & 0,67 & 0 & 0 & 4 & 0,67 \\
\hline$-\quad 20-35$ th & 109 & 18,4 & 76 & 12,85 & 256 & 43,31 & 49 & 8,29 & 490 & 82,85 \\
\hline$-\quad>35$ th & 40 & 6,7 & 11 & 1,86 & 39 & 6,59 & 7 & 1,33 & 97 & 16,48 \\
\hline \multicolumn{11}{|l|}{ Pendidikan Ibu } \\
\hline$-\quad S D$ & 5 & 0,84 & 15 & 2,54 & 34 & 5,75 & 0 & 0 & 54 & 9,13 \\
\hline - SMP & 66 & 11,16 & 34 & 5,75 & 105 & 17,17 & 20 & 3,38 & 225 & 37,46 \\
\hline - SMA & 78 & 13,19 & 38 & 6,43 & 160 & 27,07 & 36 & 6,72 & 312 & 53,41 \\
\hline$-\quad \mathrm{PT}$ & 0 & 0 & 0 & 0 & 0 & 0 & 0 & 0 & 0 & 0 \\
\hline \multicolumn{11}{|l|}{ Pekerjaan Ibu } \\
\hline - Pedagang & 0 & 0 & 0 & 0 & 0 & 0 & 0 & 0 & 0 & 0 \\
\hline - Buruh/Tani & 0 & 0 & 0 & 0 & 0 & 0 & 0 & 0 & 0 & 0 \\
\hline - $\quad$ PNS & 0 & 0 & 0 & 0 & 0 & 0 & 0 & 0 & 0 & 0 \\
\hline - $\quad$ TNI/POLRI & 0 & 0 & 0 & 0 & 0 & 0 & 0 & 0 & 0 & 0 \\
\hline - Pensiunan & 0 & 0 & 0 & 0 & 0 & 0 & 0 & 0 & 0 & 0 \\
\hline - Wiraswasta & 0 & 0 & 0 & 0 & 0 & 0 & 0 & 0 & 0 & 0 \\
\hline - $\quad I R T$ & 149 & 25,21 & 87 & 14,72 & 299 & 50,59 & 56 & 9,48 & 591 & 100 \\
\hline \multicolumn{11}{|l|}{ Pendapatan Keluarga } \\
\hline$-\quad<1.500 .000$ & 44 & 7,45 & 39 & 6,60 & 49 & 8,30 & 17 & 2,88 & 149 & 25,23 \\
\hline - $\quad 1.500 .000-2.500 .000$ & 104 & 17,60 & 39 & 6,60 & 243 & 41,12 & 37 & 6,22 & 423 & 71,54 \\
\hline$-\quad>\quad 2.500 .000$ & 1 & 0,17 & 9 & 1,53 & 7 & 1,19 & 2 & 0,34 & 19 & 3,23 \\
\hline 3.000 .000 & 0 & 0 & 0 & 0 & 0 & 0 & 0 & 0 & 0 & 0 \\
\hline$-\quad>3.000 .000$ & & & & & & & & & & \\
\hline \multirow{2}{*}{\multicolumn{11}{|c|}{$\begin{array}{l}\text { Jumlah Anggota Keluarga } \\
\text { Dalam Serumah }\end{array}$}} \\
\hline & & & & & & & & & & \\
\hline$-\quad \leq 4$ & 148 & 25,04 & 79 & 13,37 & 271 & 45,85 & 56 & 9,47 & 554 & 93,73 \\
\hline$-\quad>4$ & 1 & 0,17 & 8 & 1,36 & 28 & 4,74 & 0 & 0 & 37 & 6,27 \\
\hline \multicolumn{11}{|l|}{ Jenis Kelamin Anak } \\
\hline - $\quad$ Laki - Laki & 71 & 12,01 & 50 & 8,46 & 120 & 20,31 & 12 & 2,03 & 253 & 42,81 \\
\hline - $\quad$ Perempuan & 78 & 13,19 & 37 & 6,26 & 179 & 30,29 & 44 & 7,45 & 338 & 57,19 \\
\hline \multicolumn{11}{|l|}{ Berat Lahir Anak } \\
\hline$-\quad<2500 \mathrm{gr}$ & 8 & 1,35 & 0 & 0 & 21 & 3,55 & 0 & 0 & 29 & 4,90 \\
\hline$-\quad 2500-4000 \mathrm{gr}$ & 141 & 23,86 & 87 & 14,72 & 278 & 47,05 & 56 & 9,47 & 562 & 95,10 \\
\hline$-\quad>4000 \mathrm{gr}$ & 0 & 0 & 0 & 0 & 0 & 0 & 0 & 0 & 0 & \\
\hline \multicolumn{11}{|l|}{ Status ASI } \\
\hline - Eksklusif & 128 & 21,66 & 65 & 10,99 & 223 & 37,73 & 42 & 7,11 & 458 & 77,49 \\
\hline - $\quad$ Tidak Eksklusif & 21 & 3,55 & 22 & 3,72 & 76 & 12,86 & 14 & 2,38 & 133 & 22,51 \\
\hline \multicolumn{11}{|l|}{ Status Imunisasi } \\
\hline - $\quad$ Belum Lengkap & 16 & 2,71 & 31 & 5,25 & 95 & 16,07 & 4 & 0,68 & 146 & 24,71 \\
\hline - Lengkap & 128 & 21,66 & 56 & 9,48 & 204 & 34,52 & 52 & 8,78 & 440 & 74,44 \\
\hline - Tidak Lengkap & 5 & 0,85 & 0 & 0 & 0 & 0 & 0 & 0 & 5 & 0,85 \\
\hline
\end{tabular}

Berdasarkan tabel 2 diatas distribusi frekuensi kejadian stunting di Puskesmas Panjang Kota Bandar Lampung Tahun 2019, sebanyak 149 $(25,22 \%)$ sangat pendek, $87(14,73 \%)$ pendek, 299 $(50,59 \%)$ normal, $56(9,46 \%)$ tinggi.
Tabel 2 Distribusi Frekuensi Kejadian Stunting di Puskesmas Panjang Bandar Lampung Tahun 2019

\begin{tabular}{clrr}
\hline No & \multicolumn{1}{c}{ Kategori } & $\mathrm{F}$ & \multicolumn{1}{c}{$\%$} \\
\hline 1 & Sangat Pendek & 149 & 25,22 \\
2 & Pendek & 87 & 14,73 \\
3 & Normal & 299 & 50,59 \\
4 & Tinggi & 56 & 9,46 \\
& & 591 & 100,00 \\
\hline
\end{tabular}




\section{PEMBAHASAN}

Distribusi frekuensi Kejadian Stunting di Puskesmas Panjang Bandar Lampung Tahun 2019

Saat ini stunting menjadi topik perbincangan di dunia gizi dan kesehatan karena salah satu masalah gizi ini menjadi ancaman terbesar bagi kualitas hidup manusia di masa mendatang. Tidak hanya mengenai tinggi badan, stunting menjadi penting untuk diberantas karena terkait dengan hambatan pertumbuhan otak anak, penurunan kualitas belajar hingga penurunan produktivitas di usia dewasa dan ancaman peningkatan penyakit tidak menular (obesitas, hipertensi, diabetes mellitus, dsb).

Berdasarkan hasil penelitian kategoti Normal memiliki jumlah tertinggi sebesar 299 orang $(50,59 \%)$, namun kategor pendek sebesar 87 orang dengan $14,73 \%$ dan Sangat pendek sebesar 149 orang $(25,22 \%)$. Total stunting $39,95 \%$. Hasil penelitian ini sejalan dengan penelitian yang dilakukan oleh Oktarina, Zilda dan Sudiarsih, Triniti (2012) yang dipublikasikan dalam Jurnal Gizi dan Pangan, Volume 8, Nomor 3, November 2013 dengan judul "Faktor Risiko Stunting Pada Balita (24 - 59 Bulan) Di Sumatera" yang melibatkan subjek 1239 balita, data diambil menggunakan hasil Riskesdas 2010. Hasil penelitian didapatkan prevalensi balita stunting sebesar $44,1 \%$.

Menurut pendapat peneliti, apabila diakumulasikan prevalensi balita stunting di Puskesmas Panjang sebesar 39,95\%, angka tersebut sangat tinggi dan menjadi masalah kesehatan karena prevalensinya lebih dari sama dengan 20\%. Jika ditinjau dari karakteristik responden dengan balita stunting, $120(20,29 \%)$ dengan pendidikan ibu rendah (SD, SMP). Ibu yang berpendidikan tinggi cenderung akan membuat keputusan yang akan meningkatkan gizi dan kesehatan anak - anakanya dan cenderung memiliki pengetahuan gizi yang baik pula, sehingga ibu akan tahu bagaimana mengolah makanan, mengatur menu makanan dan menjaga mutu kebersihan makanan dengan baik. Berdasarkan pekerjaan ibu, 591 (100\%) sebagai ibu rumah tangga. Pekerjaan ibu berkaitan dengan pola asuh anak dan status ekonomi keluarga. Disatu sisi ketika ibu bekerja anak tidak terawat, namun di pihak lain ibu bekerja dapat membantu pemasukan keluarga, karena bekerja merupakan factor penting dalam menentukan kualitas dan kuantitas pangan.

Berdasarkan pendapatan keluarga, sebanyak $226(38,25 \%)$ memiliki pendapatan cukup sampai rendah. Pendapatan keluarga yang cukup sampai rendah berkaitan dengan daya beli keluarga terhadap pangan yang rendah pula sehingga zat gizi yang dikonsumsi pun akan rendah. Untuk jumlah anggota keluarga dalam serumah, $9(1,53 \%)$ sebanyak $>4$ orang. Jumlah anggota keluarga berkaitan dengan penyediaan dan distribusi pangan dalam keluarga. Pada rumah tangga yang memiliki jumlah anggota keluarga relative banyak dapat menurunkan kuantitas dan kualitas konsumsi pangan.

Karakteristik selanjutnya berdasarkan jenis kelamin anak, sebanyak $121(20,47 \%)$ stunting dialami baduta jenis kelamin laki - laki dan 115 $(19,45 \%)$. Laki - laki berisiko untuk menjadi stunting karena ukuran tubuh lebih besar dan membutuhkan asupan energy lebih besar, jika tidak terpenuhi dalam jangka waktu lama akan meningkatkan risiko gangguan pertumbuhan dan akan berakibat stunting. Berdasarkan status ASI Eksklusif, 43 $(7,27 \%)$ dengan status ASI Tidak Eksklusif. Status ASI Eksklusif berkaitan dengan kejadian stunting, saat bayi mulai dikenalkan dengan MPASI sebelum waktunya, hal ini membuat bayi lebih tertarik dengan makanan tersebut dibandingkan ASI, bayi akan merasa kenyang dan tidak sempat minum ASI, lama - lama frekuensi minum ASI akan terus menurun samapai pada akhirnya bayi tidak mau minum ASI, akibatnya bayi kehilangan nutrisi penting yang terdapat pada ASI sehingga pertumbuhan jadi terhambat.

\section{KESIMPULAN}

Kejadian stunting di Puskesmas Panjang Kota Bandar Lampung sebesar 39,95\%. Dengan mendata karakteriktik responden seperti umur ibu, pekerjaan ibu, penddikan, jumlah pendapatan keluarga, jumlah anggota keluarga dalam serumah,jenis kelamin anak, bderat lahir anak,status ASI dan status imunisasi

\section{SARAN}

Data hasil penelitian ini dapat menjadi acuan untuk melakukan kegiatan berupa pemberian informasi baik melalui media cetak, media elektronik maupun media sosial tentang pencegahan stunting.

\section{DAFTAR PUSTAKA}

Almatsier, S. 2011.Gizi Seimbang Dalam Daur Kehidupan. Jakarta: Gramedia Pustaka Utama

Dinas Kesehatan Provinsi Lampung.2016. Ayo Cegah Stunting. 28 Januari 2018. http://dinkes.lampungprov.go.id/Ayo Cegah Stunting - Dinkes Provinsi Lampung.html

Direktorat Bina Gizi. 2015. Sistem Informasi Gizi (SIGIZI). $\quad 16 \quad$ Januari 2018. 
http://gizi.depkes.go.id/sigizi/2015

KemenkesRI. 2010. Keputusan menteri kesehatan RINo.1995/Menkes/SKI XII/2010 tentang Standar Antropometri Penilaian Status Gizi Anak.

Lathifah, N. S. (2016). Gambaran Pengetahuan Ibu tentang Keluarga Sadar Gizi (Kadarzi) di Lingkungan Pulau Pasaran Kelurahan Kota Karang Kecamatan Teluk Betung Timur Kota Bandar Lampung. Jurnal Kesehatan, 7(1), 85-89.

Marimi.

2013. GizidalamKesehatanReproduksi.Pusta kaPelajar.Yogyakarta.

Notoatmodjo, S. 2012. Metodologi Penelitian Kesehatan. Jakarta: Rineka Cipta.

Oktarina, Zilda \& Sudiarti, Trini. November 2013." Faktor Risiko Stunting Pada Balita (24 - 59 Bulan) Di Sumatera", Jurnal Gizi dan Pangan,

http://journal.ipb.ac.id/index.php/igizipangan/ article/view/7977

Priyono et al. Mei 2015." Determinan Kejadian
Stunting pada Anak Balita Usia 12 - 36

Bulan di Wilayah Kerja Puskesmas Randuagung Kabupaten Lumajang", e-Jurnal Pustaka Kesehatan, https://jurnal.unej.ac.id/index.php/JPK/article/ download/.../2159

Pusat Data dan Infomasi.Situasi Balita Pendek.Kementerian Kesehatan RI

Soetjiningsih,RanuhG.2013.Tumbuh Kembang AnakEd.2.EGC.Jakarta.

Supariasa, Bakri.B \&Fajar, I. 2012. Penilaian Status Gizi.Jakarta. EGC

Wiyogowati,C.2012.Kejadian Stunting Pada Anak Berumurdi BawahLima Tahun(0-5 Bulan) diProvinsi Papua Barat Tahun 2010 (Analisis Data Riskesdas Tahun2010).Skripsi FakultasKesehatan Masyarakat, Universitas IndonesiaDepok.

Zahraini, Yuli. 2017."Stunting dan Kesehatan Lingkungan". 28 Januari 2018. http://gizi.depkes.go.id/Gizinet - Stunting dan Kesehatan Lingkungan.html 